\title{
O uso da internet em rádios AM no Piauí: novas perspectivas
}

\author{
The use of the internet in the AM radio Piaui: new perspectives
}

\author{
Leila Lima de Sousa ${ }^{[a]}$, Orlando Maurício de Carvalho Berti ${ }^{[b]}$, Samara Kelly Alves da Costa ${ }^{[\mathrm{c}]}$
}

[a] Graduanda e pesquisadora discente do curso de Comunicação social (habilitação em Jornalismo) da Universidade Estadual do Piauí (UESPI), bolsista do Programa de Bolsa de Iniciação Científica (PIBIC), Teresina-PI - Brasil, e-mail: leila.zinha@hotmail.com

[b] Doutorando e Mestre em Comunicação Social pela Universidade Metodista de São Paulo (UMESP), professor assistente I da Universidade Estadual do Piauí (UESPI), pesquisador e extensionista nas áreas de comunicação e tecnologias atuais, TeresinaPI - Brasil, e-mail: orlandoberti@yahoo.com.br

[c] Graduanda e pesquisadora discente do curso de Comunicação Social (habilitação em Jornalismo) da Universidade Estadual do Piauí (UESPI), bolsista do Programa de Bolsa de Iniciação Científica (PIBIC), Teresina, PI - Brasil, e-mail: samarakellys@hotmail.com

\section{Resumo}

O presente trabalho apresenta como as rádios em ondas médias (AM) de Teresina, capital do Piauí (Brasil), utilizam novas formas de processos comunicacionais por meio da Internet. O alcance do rádio pelo mundo se intensificou, demandando que esse meio de comunicação esteja se adaptando em relação à difusão de seus conteúdos através da internet. Poucos são os registros acerca do assunto no contexto estadual que permitem a ampliação do conhecimento específico. Este artigo tem o objetivo de preencher esta lacuna historiográfica. Os autores fizeram pesquisa documental e realizaram entrevistas com personagens das rádios Pioneira e Antares da cidade de Teresina (PI), que são os objetos de estudo desse artigo.

Palavras-chave: Rádios AM. Internet. Interatividade. Rádio Pioneira. Rádio Antares.

\begin{abstract}
This paper shows how the radio on medium wave (AM) of Teresina, capital of Piani (Brazil), use new forms of communication processes via the Internet. The reach of radio the world has intensified, this media is adapting to the spread of its content via the Internet. There are few records about the subject in the context state. This article aims to fill this historiographical gap. The authors undertook archival research and conducted interviews with characters from radio Pioneer and Antares the city of Teresina (PI), which are the objects of study of this article.
\end{abstract}

Keywords: AM Radio. Internet. Interactive. Radio Pioneer. Radio Antares. 


\section{Introdução}

O rádio foi o primeiro meio de comunicação eletrônico a penetrar o espaço doméstico, atingindo lares, instigando corações e mentes, formando e informando gerações. No século XX, período de seu auge, era considerado por homens da classe média como um hobby e também como um serviço público. Alguns acreditavam que o mecanismo poderia vir a substituir a telefonia fixa e outros, como Edgard Roquete Pinto (FERRARETO, 2000 , p. 95-96), sonhavam em utilizar o rádio para educar as massas.

O meio de comunicação radiofônico tem uma trajetória, desde a simples experiência de transmissão de sinais até sua difusão por meios digitais, sempre se adaptando às mudanças impulsionadas pelas revoluções tecnológicas.

Durante a segunda metade do século XX essa mídia de massa passou por transformações, crises e fortalecimento. No século XXI, as afirmações sobre a extinção do rádio já são quase inexistentes, já que esse meio de comunicação vive um novo desafio de adaptação, por sinal bem crescente e abrangente. As transmissões radiofônicas encontraram uma nova forma de abrangência por meio da tecnologia da internet.

Com o advento da Grande Rede Mundial de Computadores, o rádio ganhou a possibilidade de ter sua programação transmitida não só em esfera local, mas também global. "Glocalização" foi a denominação dada por Manuel Castells (2003) para uma programação local disponível de forma global.

Comisso, tem maioralcance, atingindo populações geograficamente distantes dos grandes centros urbanos e analfabetos. A portabilidade, propiciada pelo transistor, tem sido um dos elementos fundamentais. Num período de tecnologia digital, o rádio soma a esta abrangência a possibilidade de transmissão de uma mesma mensagem de caráter local em esfera mundial (CUNHA, 2004, p. 11).

O rádio, aliado à internet, ganha novas formas de interação com o público, pois o usuário pode definir seu grau de participação por meio de chats e e-mails, já que a comunicação interativa e coletiva é característica inerente da internet. Nela é possível a coexistência e a complementaridade de diversas mídias, que ligadas à estrutura do hipertexto (o usuário pode gerenciar sua navegação entre os conteúdos disponíveis), possibilitam ao receptor uma nova forma de acesso da informação. A comunicação do usuário fica mais eficaz e imediata do que como era feito antes, por meio de cartas e telefone.

Entender os processos comunicacionais do fenômeno dessa midiatização entre rádios e seu advento para a internet é o que caracteriza o principal cerne deste artigo. Procura-se desvendar como as rádios AM (de transmissão em amplitude modulada), mais tradicionais que as FM (de transmissão em frequência modulada), do Piauí têm seus novos processos comunicacionais via Grande Rede Mundial de Computadores.

Para isso, faz-se um estudo de caso com as duas principais emissoras AM do Piauí que atualmente já dispõem sua programação na internet: a Rádio Antares e a Rádio Pioneira de Teresina, ambas localizadas na capital piauiense.

\section{Novas perspectivas para o rádio}

A tecnologia da internet oferece um futuro diferente aos meios de comunicação. No caso das emissoras de rádio, as ferramentas de internet e satélite liberam as emissoras da limitação de frequência, deixando seu alcance eminentemente territorial para alcance mundial (mesmo não estando em satélite). Em tempo real, ouvintes de qualquer parte do mundo podem acompanhar a programação dos meios de comunicação radiofônicos locais.

Para se adaptar a essa tecnologia, os meios radiofônicos integram novos recursos à sua mensagem. Recursos esses que permitem ao ouvinte novas formas de interatividade, não mais por meio de cartas ou por telefonemas, como era feito antes. Nesse novo contexto, o ouvinte tem a oportunidade de interagir de uma forma mais direta com o emissor da mensagem.

A disponibilização de emissoras online se torna fácil por alguns motivos: a concessão para rádio na internet não é necessária, os equipamentos são simples e acessíveis (apenas um computador e como item opcional uma mesa de som), os conteúdos podem ser acessados em dias e horários mais convenientes para o consumidor midiático (já que no ciberespaço existe a questão do arquivo dos conteúdos, que podem ser acessados a qualquer momento). 
O uso de dispositivos digitais, como os MDs, CDs e computadores, trouxe mudanças significativas no contexto das rádios tradicionais. O que antes era feito em formato analógico agora passa a ser digitalizado. E é essa digitalização das emissoras radiofônicas que acaba levando o rádio para a rede e tornando-o um meio dotado de recursos multimídia.

Por meio desse novo contexto que impulsiona o rádio para além dos limites da territorialidade e que possibilita uma interação horizontal-em que o ouvinte pode manter contato direto com a emissora de forma mais consistente - e da convergência das mídias que agregam recursos de vídeo, texto e linksàs mensagens tradicionais, possibilita-se ao rádio tornar-se não só emissor, mas sim um meio multimídia.

O rádio sai de sua perspectiva histórica, como ressalta o professor Moacir Barbosa de Sousa (2005) ao destacar historicamente a evolução do rádio, principalmente da sua caracterização elitista para a sua caracterização popular.

Segundo a Pesquisa Nacional por Amostragem Domiciliar (PNAD) (2009), o aparelho de rádio está presente em $88,9 \%$ dos lares brasileiros, mostrando ainda o poder desse tipo de meio massivo de comunicação entre os moradores do Brasil.

\section{Rádios AM}

Modulação em amplitude é o que se usa na transmissão AM do rádio, também conhecida como emissora de ondas médias (OM). Essa transmissão se dá em várias bandas de frequência e, em meados do século XX, as frequências AM foram fundamentais na vida do brasileiro.

Segundo Luiz Artur Ferrareto (2000, p. 95-97), as primeiras transmissões AM no Brasil surgiram com a emissora de Roquette-Pinto, que em 1923 fundou a Rádio Sociedade do Rio de Janeiro. Essa rádio transformou-se, em 1936, em Rádio Ministério da Educação, propagando o ensino a distância.

As emissoras de rádio AM destinam a maior parte do seu horário, cerca de $70 \%$, aos programas definidos como de jornalismo e variedades; e o restante, $30 \%$, para programas puramente musicais. Os locutores dessas rádios exercem muito carisma sobre os seus ouvintes e costumam ter como característica de comunicação uma voz marcante, o que é quase um padrão de voz nessas emissoras.

As emissoras AM também têm entre suas características a presença de um ouvinte de faixa etária mais elevada; elas têm uma ligação maior com esse ouvinte, utilizando linguagem mais intimista e que aproxima o emissor do receptor.

No Piauí, as rádios AM ainda são em maior número que as FM, principalmente no interior do Estado, onde esse tipo de emissora radiofônica ainda tem o grande papel de avisar aos moradores sobre benefícios sociais e momentos políticos ou de dar simples avisos de parentes e amigos que moram em outras regiões da cidade, do Estado e até do País. Segundo Orlando Maurício de Carvalho Berti (2010), ${ }^{1}$ no Piauí há atualmente: 24 emissoras de rádio que operam em FM; 48 emissoras AM, uma sendo em OM; 6 emissoras educativas; e 72 emissoras de rádio comunitária.

\section{Rádio Pioneira 1150 AM}

A Rádio Pioneira de Teresina é uma das emissoras radiofônicas mais antigas e com maior poder de penetração no Piauí. Essa emissora foi criada em 1962 pela Arquidiocese de Teresina, integrando-se ao Movimento de Educação de Base (MEB).

O Arcebispo de Teresina, Dom Avelar Brandão Vilela, imprimiu à nova rádio um padrão jornalístico mais afinado com as redes nacionais, com uma programação jornalística mais popular, mas também de cunho educativo. A despeito do caráter educativo e da vinculação da emissora à Arquidiocese, desde o início de sua fundação ficou claro que D. Avelar apostaria na profissionalizaçãoe na racionalização das atividades radiofônicas enuma linha de programas populares. [...] Embora não tivesse sido a primeira emissora da cidade, a 'Pioneira' conquistou o posto de rádio mais sintonizada do Piauí, durante as décadas de 60 e 70. Da unidade móvel (um automóvel Kombi, com um sistema de transmissão acoplado), a rádio cobria eventos de diversos tipos na capital do Piauí e até no interior do Estado (RUFINO; SAID, 2007, p. 7-9).

1 Dados do primeiro semestre de 2010. 
A Rádio AM Pioneira tem um site (Figura 1), cujo endereço é: <http://www.radiopioneira.am.br>, onde sua programação é veiculada. Os ouvintes podem interagir com os locutores ao vivo, por meio de e-mails, sistema de mensagem instantânea (messenger ou msn) e ainda pela própria página da emissora, onde se fazem pedidos, reclamações, elogios, dão-se sugestões ou tem-se o link ao vivo da rádio.

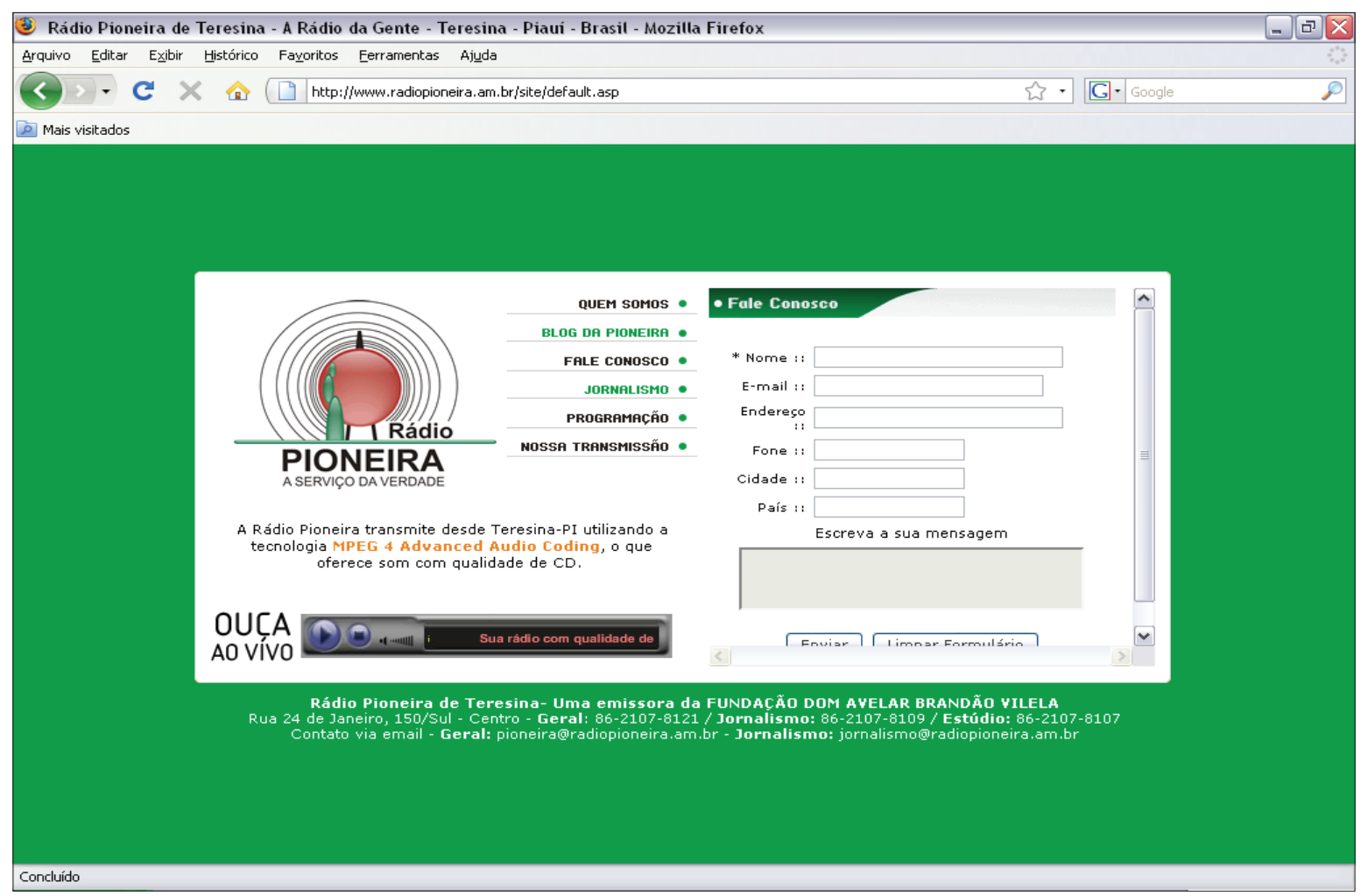

Figura 1 - Sítio da Rádio Pioneira AM de Teresina

Fonte: RÁDIO PIONEIRA, 2010.

Para a produção do artigo houve uma visita à Rádio Pioneira, onde pôde-se analisar como essa rádio está se adaptando em relação à difusão de seus conteúdos por meio da internet. O coordenador de jornalismo da AM Pioneira de Teresina, James Almeida (2009), disse que percebe aumento na audiência da rádio graças ao fato de que muitas pessoas que moram longe de Teresina, mas que têm vínculos com a cidade, podem acessar o site, ouvir a rádio e inclusive interagir com os jornalistas. Esses ouvintes, ou web-ouvintes, têm origem territorial de praticamente todos os cinco continentes.

Almeida (2009) destacou que todos os comunicadores da rádio (entre radiojornalistas e responsáveis por entretenimento) estão se adaptando a essa nova realidade do radiojornalismo aliado à internet. A locutora e produtora da AM Pioneira de Teresina,
Rosangela Mourão Veras (2009), expôs que locais aos quais a frequência da rádio não chega são beneficiados graças à sua versão online, já que os ouvintes dessas localidades interagem constantemente com a rádio.

Rosangela Veras (2009) também falou que já recebeu e-mails de ouvintes de outros continentes, como da França, da Suíça, da Itália e dos Estados Unidos, o que confirma a "glocalização" de Manuel Castells (2003), em que a figura do local e do global encontram-se na mesma interface comunicacional.

A Rádio Pioneira tem, além da versão online exposta no seu próprio site, um link em um dos sítios noticiosos de Teresina, no site Acesse Piauí (http:/ / www.acessepiaui.com.br) (Figura 2).

O linké uma parceria entre a emissora AM de Teresina e o sítio noticioso Acesse Piauí: 


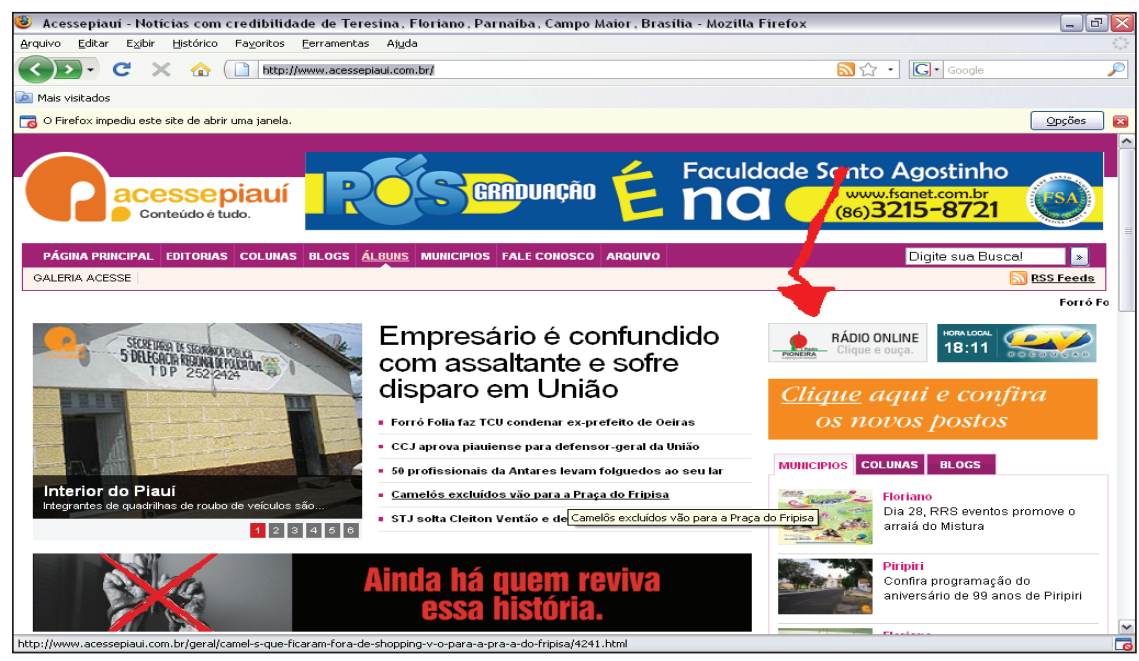

Figura 2 - Página do sítio noticioso Acesse Piauí, que dispõe um link para a página eletrônica da Rádio Pioneira AM de Teresina

Fonte: ACESSE PIAUÍ, 2010.

\section{Rádio Antares AM 800}

A Rádio Antares existe desde o dia 3 de outubro de 1988, ela é uma rádio AM estatal (pertencente ao poder público) ligada ao Governo do Piauí. A emissora nasceu no mandato de Alberto Tavares Silva (PMDB), que deu o nome da rádio em homenagem à quinta estrela mais visível do céu.

A Fundação Antares, ao longo de sua existência, sofreu inúmeras modificações. Por ser uma emissora que está sob o controle do Estado, a cada governo sua estrutura e sua administração eram mudadas. No ano de 2003, sob o primeiro governo de Wellington Dias (PT), a rádio viveu mais uma nova fase.

Durante todo o ano de 2003, a rádio ficou fora do ar, sob determinação judicial, com a finalidade de ser reformada sua estrutura e toda a sua administração. Desde então, a Rádio Antares segue os padrões que são conhecidos hoje.

A Fundação Antares Rádio e Televisão Educativa do Piauíainda não possui um site próprio e, em virtude disso, a programação da rádio é transmitida via internet por meio do site do Governo do Estado do Piauí (http://www.piaui.pi.gov.br) (Figura 3).

O embasamento da pesquisa sobre a veiculação da programação da Rádio Antares por meio

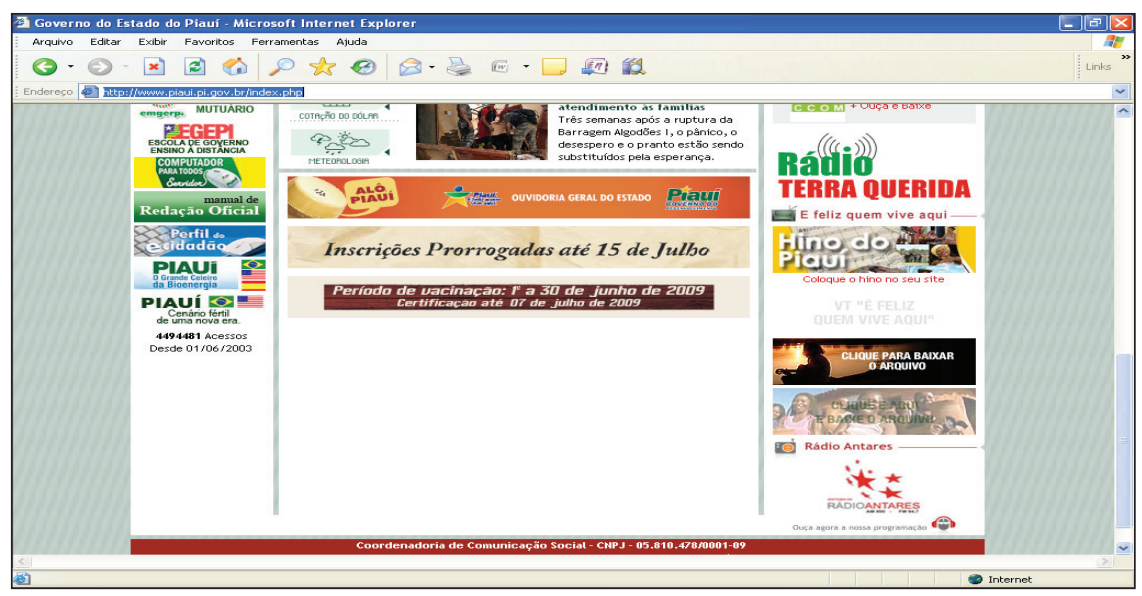

Figura 3 - Sítio do Governo do Piauí, onde o link da AM Antares é fornecido Fonte: PIAUÍ, 2010. 
também da internet deu-se por intermédio de entrevista realizada com a diretora da emissora, a jornalista Cláudia Marques (2009), e com a produtora do Jornal Antares Notícias, Marcilany Rodrigues (2009).

Segundo Cláudia Marques (2009), a internet é mais uma opção para que as rádios venham a atingir mais ouvintes. $\mathrm{O}$ ouvinte agora pode ser alcançado por meio da internet, que ganha a cada dia mais adeptos.

Cláudia Marques (2009) disse, ainda, que a internet é uma nova ferramenta de difusão das transmissões radiofônicas que não pode serignorada pelas rádios. As empresas têm que visualizar as novas tecnologias como aliadas e usá-las em benefício próprio. A versão online das rádios demonstra aos ouvintes que a emissora está atenta às novidades do setor e interessada em ampliar suas transmissões.

Sobre o alcançe da rádio aos locais onde a frequência não chega, a jornalista e diretora da Rádio Antares, Cláudia Marques, detalha que:

é difícil afirmar isso de uma forma simples, sem levar em conta os aspectos econômicos. A internet leva o sinal da rádio para o mundo todo, mas ainda tem um acesso restrito principalmente para as camadas de baixa renda. Nos municípios do interior do Estado, por exemplo, aos quais o sinal da rádio não chega, o acesso à internet ainda é muito limitado por carências financeiras. Sendo assim, sob esse aspecto, a internet não influi muito no aumento de audiência. Em contrapartida, nosso sinal navega pelo mundo, em cidades e países desenvolvidos, aos quais o sinal da rádio não chegaria pelos sistemas normais de transmissão. Dessa forma, ampliamos a possibilidade de acesso à nossa programação. Durante os eventos ao vivo que transmitimos, como Salipi e Folguedos, vários palestrantes de outras localidades repassam nosso endereço eletrônico para que amigos e familiares acompanhem as transmissões via internet (MARQUES, 2009).

A produtora do Jornal Antares Notícias, da Rádio Antares, Marcilany Rodrigues (2009), expôs que não acha que a emissora tenha como aferir nível de audiência da rádio após difundir seu conteúdo por meio da web, já que nunca foi realizada uma pesquisa voltada a esse propósito e, segundo ela, no link onde é oferecido o conteúdo da rádio não existe nenhuma forma de interação com os internautas.

Marcilany Rodrigues (2009) falou que com a internet pode igualar níveis de acesso entre rádios AM e FM, já que hoje, graças ao avanço das tecnologias, é possível sintonizar uma rádio FM via celular, o que não acontece com uma AM. Para ela, por meio da internet os acessos podem ser igualados, com espaço de veiculação das duas modalidades de rádio.

\section{As consequências e interfaces do uso da internet em rádios AM no Piauí e suas novas perspectivas}

O papel do rádio continua mais que importante para formar, informar, entreter e construir uma sociedade melhor. Com o advento e fortalecimento das emissoras em FM (frequência modulada), nos anos 80 e 90 do século XX, as emissoras AM começaram a perder sua hegemonia. Uma das formas de ter seu espaço de volta, e principalmente continuar forte como meio de comunicação de massa, foi diversificar sua programação, não mais em um ambiente físico, territorial e analógico como por décadas foi o rádio, mas também adentrando para as perspectivas das tecnologias atuais ou, como destaca Pollyana Ferrari (2003), fazer crossmidia, que é o oferecimento de conteúdo do mesmo grupo de mídia em diversas plataformas.

Nos casos estudados (das AM Antares e Pioneira de Teresina - duas das mais ouvidas, respeitadas e tradicionais emissoras radiofônicas do Piauî), essa crossmidia se dá via internet: no caso da Rádio Antares, via sítio do Governo do Estado do Piauí; e no caso da Rádio Pioneira, via sítio próprio e também lincado em sítio jornalístico piauiense (Acesse Piau1). O fato de estarem na Grande Rede Mundial de Computadores só ajuda a diversificar, melhorar, ampliar e consoar com as tendências atuais.

As duas emissoras estudadas diversificam suas programações a partir do momento em que interagem com os usuários não mais de suas formas tradicionais (por meio de telefones, cartas e bilhetes), mas também por meio de e-mails, mensagens instantâneas e espaços virtuais próprios de participação.

As AM Antares e Pioneira de Teresina melhoraram ao estarem na internet porque instigaram seus comunicadores a antenarem-se com as novas tecnologias e isso termina também ampliando a diversificação comunicacional, tendo mais fontes, 
mais responsabilidade e, inclusive, retroalimentando, com isso, públicos tradicionais (os do território) ainda avessos ou excluídos das novidades tecnológicas.

Ao estarem consonantes com as tendências não perdem espaço para os novos meios, só garantem a fidelização do público antigo e ganham novos consumidores de entretenimento e notícia, garantindo assim a sobrevivência dessas emissoras radiofônicas do Piauí.

As rádios AM Antares e Pioneira já instigam outras emissoras da capital e do Estado a fazerem o mesmo procedimento, tendo quintuplicado o número de emissoras AM do Piauí na internet nos anos de 2009 e 2010.

\section{Conclusão}

Após analisar os sites, onde são veiculados os conteúdos das duas rádios que são objeto deste estudo, e os depoimentos de como funciona a inserção do conteúdo dessas rádios na internet, percebe-se que a Rádio Pioneira de Teresina permite ao ouvinte maior interação com os programadores da rádio do que a Rádio Antares.

No site da Rádio Pioneira é disponibilizado um espaço para que o público ouvinte digite seus dados pessoais e entre em contato, dando sugestões e criticando, dentre outras coisas.

A Rádio Antares, apesar de disponibilizar seu conteúdo via internet, não possui um espaço próprio, o que não permite ao ouvinte uma interação com os que realizam a programação da rádio.

Por meio da análise também observa-se que a rádio veiculada por meio das ferramentas de difusão da internet possibilita aos ouvintes de outros lugares, não só do seu país de origem, mas de todo o mundo, acompanhar frequentemente o que é exposto por esses meios, o que se encaixa perfeitamente na denominação de "glocalização" proposta pelo autor Manuel Castells (2003).

Tendo como base o estudo, nota-se que os produtores dessas rádios acreditam sim que a internet veio como forte aliada para o alcançe de um maior público. É evidente que essemeio, sendousado de forma correta, pode vir a propagar, mundialmente, ainda mais o conteúdo dos meios de comunicação locais.

Mesmo tendo despertado para a difusão de seus conteúdos por meio da internet, as rádios estudadas - Rádio Pioneira de Teresina e Rádio Antares
AM 800 - estão sendo acompanhadas via internet, mas sua programação e a linguagem radiofônica ainda não foram adaptadas à veiculação por meio da rede.

Então, chega-se à conclusão de que deve-se fazer uma análise do que é ofertado pelas emissoras por meio dos sites, afinal, nem todo áudio disponibilizado na rede pode ser considerado como rádio. Muitas emissoras apenas colocam sua programação para ser veiculada pela internet por meio de um link. A essas rádios, Trigo de Souza (apud BUFARAH Jr., 2004, p. 8) denominou de rádios online. Segundo Bufarah, essa categoria cabe ainda ser subdividida em dois grupos:

os das emissoras que usam seus sites como mais um canal de comunicação com seus ouvintes, variando os níveis de interatividade, onde o usuário participa mais da programação através de chat, e-mails, promoções; e as emissoras que produzem e disponibilizam seus programas utilizando o suporte multimídia da rede para agregarem serviços especializados aos programas, inclusive possibilitando a escolha de produtos radiofônicos já veiculados (BUFARAH Jr., 2004, p. 8).

Deve-se atentar, também, para as emissoras que utilizam o site apenas como forma institucional. Essa categoria é denominada e classificada por Trigo de Souza (apud BUFARAH Jr., 2004, p. 8) como offline, pois não disponibilizam seu áudio na rede. Outra categoria recebe a denominação, segundo Trigo de Souza, de NetRadios. São rádios que nascem na própria rede e sua transmissão é feita exclusivamente pela internet.

Então, pode-se perceber que as rádios Pioneira e Antares são, segundo Trigo de Souza, rádios online, pois disponibilizam sua programação para ser veiculada pela internet por meio de um link e, no caso da Pioneira, o site não é utilizado apenas de forma institucional.

\section{Referências}

ACESSE PIAUÍ. Disponível em: <http://www. acessepiaui.com.br>. Acesso em: 1 jul. 2010.

ALMEIDA, J. Rádio Pioneira. Entrevista concedida a Samara Costa em 26 de junho de 2009. Teresina, PI. 
BERTI, O. M. de C. B. Para entender as rádios comunitárias do Piauí. Teresina: EDUESPI, 2010. No prelo.

BUFARAH Jr., Rádio na internet: desafios e possibilidades. In: CONGRESSO BRASILEIRO DE CIÊNCIAS DA COMUNICAÇÃO - NP 06 RÁDIO E MÍDIA SONORA, 27.; ENCONTRO DOS NÚCLEOS DE PESQUISA DO INTERCOM, 4., 2004, Porto Alegre. Anais... Porto Alegre: Sociedade Brasileira de Estudos Interdisciplinares da Comunicação, 2004.

CASTELLS, M. A galáxia da internet: reflexões sobre a internet, os negócios e a sociedade. Rio de Janeiro: Jorge Zahar, 2003.

CUNHA, M. O tempo do radiojornalismo: a reflexão em um contexto digital. Revista Estudos em Jornalismo e Mídia, Florianópolis, v. 1, n. 1, p. 10-19, 2004.

FERRARETO, L. A. Rádio: o veículo, a história e a técnica. Porto Alegre: Sagra Luzzatto, 2000.

FERRARI, P. Jornalismo digital. São Paulo: Contexto, 2003.

MARQUES, C. Rádio Antares. Entrevista concedida a Leila Sousa em 24 de junho de 2009. Teresina, PI.

PESQUISA NACIONAL POR AMOSTRAGEM DOMICILIAR - PNAD. Porcentagem de aparelhos de rádio presentes nas residências do brasileiro. 2009. Disponível em: <http://noticas.uol.com.br/ultnot/infografico/2009/09/18/ult3224u134.jhtm>. Acesso em: 1 jul. 2010.

PIAUÍ terra querida. Governo do Estado. Rádio Terra Querida. Disponível em: <http://www.piaui.pi.gov.br>. Acesso em: 1 jul. 2010.

RÁDIO PIONEIRA - A serviço da verdade. Disponível em: <http://www.radiopioneira.am.br>. Acesso em: 1 jul. 2010.

RODRIGUES, M. Rádio Antares. Entrevista concedida a Leila Sousa em 25 de junho de 2009. Teresina, PI.

RUFINO, R. de H.; SAID, G. F. Rádio-jornalismo esportivo no Piauí: do surgimento ao auge. In: CONGRESSO NACIONAL DE HISTÓRIA DA MÍDIA, 5., 2007, São Paulo. Anais... São Paulo: Faculdade Cásper Líbero, 2007.
SOUSA, M. B. de. Do gramofone ao satélite: evolução do rádio paraibano. João Pessoa: Universidade Federal da Paraíba, 2005.

VERAS, R. M. Rádio Pioneira. Entrevista concedida a Samara Costa em 26 de junho de 2009. Teresina, PI.

Recebido: 29/03/2010

Received: 03/29/2010

Aprovado: 22/07/2010

Approved: 07/22/2010 